\title{
Temperature Effect of Elastic Anisotropy and Internal Strain Development in Advanced Nanostructured Alloys: an in-situ Synchrotron X-ray Investigation
}

\author{
Yingye Gan ${ }^{1}$, Kun Mo ${ }^{2}$, Di Yun ${ }^{3}$, David T. Hoelzer ${ }^{4}$, Yinbin Miao ${ }^{2}$, Xiang Liu ${ }^{5}$, Kuan-Che Lan ${ }^{5}$, \\ Jun-Sang Park ${ }^{6}$, Jonathan Almer ${ }^{6}$, Tianyi Chen ${ }^{2}$, Huijuan Zhao ${ }^{1^{*}}$
}

\begin{abstract}
Nanostructured ferritic alloys (NFAs) are promising structural materials for advanced nuclear systems due to their exceptional radiation tolerance and high-temperature mechanical properties. Their remarkable properties result from the ultrafine ultrahigh density Y-Ti-O nanoclusters dispersed within the ferritic matrix. In this work, we performed in-situ synchrotron X-ray diffraction tests to study the tensile deformation process of the three types of NFAs: 9YWTV, 14YWT-sm13, and 14YWT-sm170 at both room temperature and elevated temperatures. A technique was developed, combining Kroner's model and $\mathrm{X}$-ray measurement, to determine the intrinsic monocrystal elastic-stiffness constants, and polycrystal Young's modulus and Poisson's ratio of the NFAs. Temperature dependence of elastic anisotropy was observed in the NFAs. An analysis of intergranular strain and strengthening factors determined that 14YWT-sm13 had a higher resistance to temperature softening compared to 9YWTV, attributed to the more effective nanoparticle strengthening during high-temperature mechanical loading.
\end{abstract}

\section{INTRODUCTION}

The excellent material properties of nanostructured ferritic alloys (NFAs) under conditions of high temperature, high pressure, and high irradiation make them a promising structural material for use in future nuclear engineering applications [1][2]. Unlike many traditional iron-based steels, the mechanical strength of NFAs is doubled at both room temperature and elevated temperatures [3] with a creep rate of NFAs that is 6-orders lower in magnitude [4]. NFAs are also highly resistant to radiation damage in that they have the capability of limiting radiation-induced helium bubbles within an ultrafine size $(\sim 1 \mathrm{~nm})$ without forming large voids which can cause the swelling of materials [5][6][7][8]. Through the mechanical alloying processes [9][10][11][12], NFAs such as 14YWT [9][13] and EUROFER97 [14][15] were developed as high performance oxide dispersion strengthened (ODS) alloys with a high-density ultra-fine oxygen-enriched nanoclusters both within the grains and along the grain boundaries 
[16][17][18]. The Y-Ti-O-enriched nanoclusters within 14YWT were observed to be uniform in size (2$4 \mathrm{~nm}$ ), and structurally coherent with the underline ferritic matrix [13][19][20][21][22]. The induced strain energy from the solute-solute repulsion and the presence of oxygen in the form of oxygen-vacancy pair [16][17] makes these nanoclusters ultra-stable in size even at high temperatures (0.92 of the alloy melting temperature), under high pressure [23][24] and under high irradiation conditions [5][6][7]. Via Orowan strengthening, these nanoclusters effectively constrain the grain boundary activities and dislocation migrations. The nanoclusters within grain boundaries can also suppress the grain growth of NFAs during fabrication and thermal mechanical processing. Hence, the grain size of NFAs, usually in sub-micron range, is preserved after fabrication and provides additional strengthening (Hall-Petch strengthening) to the alloys [25].

In order to further enhance the material properties of NFAs, it is important to understand the mechanical behavior and material response when both external load and elevated temperature are applied. Different chemical compositions and different thermal-mechanical treatments can cause variations in the nanocluster size and grain size for different NFAs, leading to various responses to external tensile loadings [26][27][28]. In this study, we adopted a high-energy synchrotron X-ray diffraction technique to investigate the microstructural development of three types of NFAs during in-situ uniaxial tensile tests at the temperature from room temperature (RT) to $600^{\circ} \mathrm{C}$. By applying Kroner's model [29] to interpret the experimental data, the basic mechanical properties including Young's modulus and Poisson's ratio were attained with elastic-stiffness constants $\left(C_{11}, C_{12}\right.$, and $\left.C_{44}\right)$. The increase in elastic anisotropy with temperature was observed following the temperature dependence of elastic-stiffness constants. Previous studies have shown that the nanoclusters in both 14YWT and MA957 were invisible in the XRD diffraction measurement due to their non-stoichiometric nature. As the direct lattice strain measurements of nanoclusters are not applicable [30] the mean internal stresses of the ferritic matrix and strengthening factors (SFs) [31] were calculated to represent the strengthening effect of the nanoclusters during plastic deformation.

\section{MATERIALS AND EXPERIMENTAL PROCEDURE}

Three different NFAs were employed in the present study: 9YWTV [32][33], 14YWT-sm13 [34], and 14YWT-sm170 [10][35][36]. Both 14YWT-sm13 and 14YWT-sm170 have the same nominal composition: Fe-14Cr-3W-0.4Ti- $0.3 \mathrm{Y}_{2} \mathrm{O}_{3}$ (wt.\%), while the average nanoparticle size is slightly different: $\sim 3 \mathrm{~nm}$ and $\sim 4 \mathrm{~nm}$, respectively. The 9YWT has a nominal composition of Fe-9Cr-2W-0.4Ti-0.2V-0.05C$0.3 \mathrm{Y}_{2} \mathrm{O}_{3}$ with the nanoparticle size of $\sim 5 \mathrm{~nm}$.

The in-situ uniaxial tensile tests with high-energy synchrotron X-ray diffraction characterization were conducted at the 1-ID-E hutch beamline at the Advanced Photon Source at Argonne National Laboratory. The experimental setup and the specimen dimensions are shown in Fig. 1. Uniaxial tensile tests were conducted on an MTS closed-loop servo-hydraulic test frame (model 858) with a maximum force of $\pm 15 \mathrm{kN}$ [37][38]. All the NFAs were machined into the SS-J3 type tensile specimen, as shown in Fig.1. During tensile tests, each specimen was subjected to increasing uniaxial tensile stresses up to failure with a strain rate of $2 \times 10^{-4} \mathrm{~s}^{-1}$. A monochromatic $72 \mathrm{keV}$ X-ray beam, with beam-size of $100 \times 100 \mu \mathrm{m}^{2}$ was used to perform the diffraction measurements. The experiment utilized the "Hydra" detector array, which consists of four area detectors (G1-41RT), for X-ray diffraction measurements [38]. The sample to the detector distance was $\sim 1.7 \mathrm{~m}$. The NFAs were tested at various temperatures: RT, 
$300^{\circ} \mathrm{C}, 500^{\circ} \mathrm{C}$, and $600^{\circ} \mathrm{C}$ using an infra-red furnace at ambient air.

\section{RESULTS AND DISCUSSION}

\subsection{Macro-Scale Tensile Deformation}

The engineering stress-strain diagrams of the three NFA materials tested at different temperatures are shown in Fig. 2. The corresponding ultimate tensile strengths (UTS) and the yield strengths (YS) are listed in Table 1. Both UTS and YS were observed to decrease with increasing temperature, which is in accordance with previous studies on different NFAs [38][39][40][41]. Among the tested NFAs, 14YWTsm170 exhibited the best ductility at all studied temperatures; 9YWTV shows the highest strength at all studied temperatures except at $600^{\circ} \mathrm{C}$, and $14 \mathrm{YWT}$-sm 13 shows the highest UTS value at $600^{\circ} \mathrm{C}$. From $500^{\circ} \mathrm{C}$ to $600^{\circ} \mathrm{C}$, a decrease in UTS is $13.2 \%$ for $14 \mathrm{YWT}$-sm 13 , and a decrease in UTS is $11.6 \%$ for 14YWT-sm170. However, the reduction in UTS is $49.7 \%$ for 9YWTV. Obviously, at a higher temperature regime, 14YWT materials show higher resistance to temperature softening than 9YWTV.

The Debye-Scherrer rings of stress-free samples (before tensile loading) at room temperature are shown in Fig. 3. All the samples in this study show strong texture as indicated by the intensity variation around the azimuth of the Dybye-Scherrer rings. Note that the Debye-Scherrer ring of a reflection, i.e. $\{222\}$ in 14YWT-sm170, is incomplete and thus the Bragg condition at the $\phi$ of $90^{\circ}$ (or $270^{\circ}$ ) is not met. Therefore, this reflection is inappropriate for studying the lattice strain development in tensile direction. During the uniaxial tensile test, the radii of Debye-Scherrer rings decreased along the loading direction and increased perpendicular to the loading direction due to the Poisson's effect. Therefore, the lattice strain $\left(\varepsilon_{h k l}\right)$ can be determined with the corresponding $d$-spacing by the Eq. (1) [42]:

$$
\varepsilon_{h k l}=\frac{d_{\sigma}^{\phi}-d_{0}}{d_{0}},
$$

where $d_{0}$ is the reference $d$-spacing of an $\{h k l\}$ reflection before loading is applied [38], and $d_{\sigma}^{\phi}$ is the $d$ spacing of the same reflection measured along $\phi$ when the sample is subject to the applied stress $\sigma$. At $\phi=90^{\circ}$ and $270^{\circ}$, the lattice strains close to the loading direction are measured. The lattice strain development of the representative reflections of the NFAs at both room temperature and $600^{\circ} \mathrm{C}$ is shown in Fig. 4. The elastic modulus of each reflection can be attained from the slope of lattice strain vs. applied stress curve in the elastic regime. Here, the elastic modulus of each reflection clearly shows a smaller value at $600^{\circ} \mathrm{C}$ than that at room temperature. In all the cases, $\{310\}$ reflection has the lowest elastic modulus. The hook-shaped loading curve was observed in the test of 14YWT-sm170 at low temperatures (Fig. 4(c1)). Similar behavior of internal stress development has been observed in many of the materials with multiple phases: the lattice strain of the metallic matrix slightly decreases during early yielding, but increases afterwards until necking [30][38][43][44][45]. At $600^{\circ} \mathrm{C}$, temperature softening eliminates this behavior in 14YWT-sm170.

\subsection{Elasticity Properties and Elastic Anisotropy Evolution}

In order to derive important mechanical properties of the NFAs (i.e. Young's modulus and Poisson's ratio) from the results of the in-situ experiments, a reliable model is required to correlate the single grain behavior and the material bulk response. The Voigt, Reuss and Kroner models have been 
extensively used to predict the overall properties (e.g. bulk, shear and Young's moduli and Poisson's ratio) of polycrystalline materials based on their elastic-stiffness constants for monocrystalline. Unlike the Voigt and Reuss models, however, Kroner's model can be used to estimate more accurate material elastic properties due to a more reasonable assumption in the orientation dependence of elastic parameters [46][47] . Therefore, we used this model [48] to evaluate basic mechanical properties of all three NFAs. Here each grain is defined as an inclusion in a homogeneous matrix with the strain-stress relation of a grain denoted as

$$
\sigma_{i j}=\left(C_{i j k l}+r_{i j k l}(\Omega)\right) \varepsilon_{k l} \text { or } \varepsilon_{i j}=\left(S_{i j k l}+t_{i j k l}(\Omega)\right) \sigma_{k l} \text {, }
$$

where $\sigma_{i j}$ (or $\sigma_{k l}$ ) and $\varepsilon_{i j}$ (or $\varepsilon_{k l}$ ) are the stress and strain of a grain, respectively; $C_{i j k l}$ and $S_{i j k l}$ are the stiffness and compliance tensors; $r_{i j k l}(\Omega)$ and $t_{i j k l}(\Omega)$ represent the interaction among grains, and $\Omega$ is the single grain volume. When we evaluate the overall constitutive relation of the bulk material, the interactions among grains will not manifest themselves by satisfying the following equations

$$
\int_{D} r_{i j k l} d D=\int_{D} t_{i j k l} d D=0
$$

where $D$ is the bulk volume. Therefore, the strain-stress relation in bulk materials can be defined as [49]

$$
\bar{\sigma}_{i j}=\left(C_{i j k l}\right)_{B} \bar{\varepsilon}_{i j} \quad \text { or } \quad \bar{\varepsilon}_{i j}=\left(S_{i j k l}\right)_{B} \bar{\sigma}_{i j}
$$

where $\left(C_{i j k l}\right)_{B}$ and $\left(S_{i j k l}\right)_{B}$ are bulk stiffness and compliance tensors, respectively. With the elasticstiffness constants $C_{11}, C_{12}$, and $C_{44}$, the shear stiffness $c^{\prime}=\left(C_{11}-C_{12}\right) / 2$ and anisotropy parameter $A=2 C_{44} /\left(C_{11}-C_{12}\right)$ can then be evaluated respectively. According to the definition, the parameter $A$ represents the shear resistance ratio between the elastically hardest orientation and softest orientation, making it the most appropriate measurement for determining the material's elasticity anisotropy.

With respect to the NFAs at two temperature conditions $\left(\mathrm{RT}\right.$ and $600^{\circ} \mathrm{C}$ ), the elastic modulus for each reflection plane was obtained by a linear fitting of the slope of the lattice strain-applied stress curves for each reflection, listed in Table 2 . At both $\mathrm{RT}$ and $600^{\circ} \mathrm{C}$, the $\{222\}$ crystallographic planes are the strongest and the $\{200\}$ crystallographic planes are the weakest. The only exception is 14YWT-sm13 at RT, where elastic modulus of $\{110\}$ crystallographic planes are slightly larger than that of $\{222\}$ crystallographic planes, most likely due to measurement errors. The elastic moduli of all the crystallographic planes except $\{222\}$ are considerably smaller when measured at $600^{\circ} \mathrm{C}$ than those at RT, whereas $\{222\}$ crystallographic planes develop a larger modulus at $600^{\circ} \mathrm{C}$. Such phenomenon suggests a temperature dependence of the anisotropic behavior of NFAs [38][50].

The least squares estimation was used to obtain the optimized combination of elastic-stiffness constants $\left(C_{11}, C_{12}\right.$, and $\left.C_{44}\right)$ that minimize the following expression: 


$$
\sum_{h k l}\left(\frac{E_{h k l}^{\exp }-E_{h k l}^{c a l}}{E_{h k l}^{\exp }}\right)^{2}+\sum_{h k l}\left(\frac{v_{h k l}^{\exp }-v_{h k l}^{c a l}}{v_{h k l}^{\exp }}\right)^{2}
$$

where $E$ and $V$ represent the Young's modulus and Poisson's ratio. The superscript "exp" and "cal" represent the values obtained from experimental measurement and computation based on Kroner's model, respectively. The summation was done over all the measurable $\{h k l\}$ reflections. In this study, an increment of $0.5 \mathrm{GPa}$ was adopted with all elastic-stiffness constants for the optimized combination. Note that the $\{110\}$ family reflection was not included in the calculations due to its high texture that conflicts with the homogeneous matrix assumption of the Kroner model. A typical fitting result for 14YWT-sm13 at $600^{\circ} \mathrm{C}$ with the optimized elastic-stiffness constants is shown in Fig. 5. The orientation parameter $3 a$ in Fig. 5 takes the form: $3 a=3\left(h^{2} k^{2}+k^{2} l^{2}+l^{2} h^{2}\right) /\left(h^{2}+k^{2}+l^{2}\right)^{2}$.

As the incomplete diffraction ring prevented an analysis of the elastic modulus of $\{222\}$ for 14YWT-sm170, only 9YWTV and 14YWT-sm13 were analyzed to attain their elastic-stiffness constants. It was then possible to calculate the corresponding values of the shear stiffness and the anisotropy parameter. The elastic-stiffness constants obtained with Eq. (5) are listed in Table 3, and the basic properties of materials are presented in Fig. 6. As the testing temperature increases, materials' softening reflected by the decrease in Young's modulus and the increase in Poisson's ratio was observed in both NFAs (Fig. 6(a, b)). As shown in Fig. 6(c), the shear modulus decreases with the increasing temperature. The temperature dependence of bulk elastic anisotropy was studied through the development of Poisson's ratio as the function of temperature, and the materials' intrinsic monocrystal elastic anisotropy was determined through the anisotropy parameter A. As seen in Fig. 6(d), the anisotropy parameter exhibited very little change in the low-temperature regime $\left(\mathrm{T}<400^{\circ} \mathrm{C}\right)$, but dramatically increased in the hightemperature regime $\left(\mathrm{T}>400^{\circ} \mathrm{C}\right)$. This increase indicates that the elastic strain response of crystalline in the NFAs develops a higher anisotropy when loaded at high temperatures.

The orientation dependence of Young's modulus of 9YWTV and 14YWT-sm13 was then plotted in $3 \mathrm{D}$ to visually compare their elastic anisotropy (see Fig. 7). For modulus at RT and $600^{\circ} \mathrm{C}, 9 \mathrm{YWTV}$ apparently displays stronger anisotropy, meaning that the elastic modulus in 9YWTV shows the larger difference for various orientations than 14YWT-sm13.

To further investigate the anisotropic behavior of grains orienting in different directions at various temperatures, we calculated the intergranular strains $\Delta \varepsilon^{\mathrm{II}}$ to examine the difference between the real lattice strain $\varepsilon_{\{h k l\}}$ and the projected linear elastic strain accordingly, which is defined as

$$
\Delta \varepsilon^{\mathrm{II}}=\varepsilon_{\{h k l\}}-\sigma / E_{\{h k l\}}
$$

Here, plastic deformation begins within those grains that have orientations that activate their dislocation slip systems upon reaching the point of critical shear stress. Other grains at different orientations, however, sustain more loads in that they continue to respond to the load elastically, which causes a redistribution of stress among these grains. Compressive intergranular strain accumulates for the grains that first reach the yielding point, while the grains in other orientations that are plastically hard still experience a tensile intergranular strain. Therefore, the onset of the accumulating of compressive intergranular strains of grain aligned in softer orientations is an indication of the elastic anisotropy 
[50][51][52][53]. As shown in the variation of the compressive intergranular strains with applied stress for $\{110\}$ grains in the NFAs (see Fig. 8) the onset of compressive intergranular strain for the 14YWTsm170 and 14YWT-sm13 alloys is quite similar at $500^{\circ} \mathrm{C}$ and $600^{\circ} \mathrm{C}$, denoting an insignificant softening at these temperatures. Note that the elastic anisotropy is also restrained in 14YWT while 9YWTV at $500^{\circ} \mathrm{C}$ obviously shows a higher yielding point than at $600^{\circ} \mathrm{C}$. With the rise in temperature, the compressive intergranular strain starts to accumulate at a much lower external loading value in 9YWTV, indicating an obvious "softening" of the grains.

\subsection{Mean Internal Stress}

In order to understand the mechanically strengthening mechanism during the plastic deformation and the loading status for both ferritic matrix and nanoparticles, we calculated the mean internal stress of the matrix and compared it with the externally applied stress. The difference between the internal stress and the externally applied stress refers to the load status of various phases within the NFAs. It can help explain the nanoparticles strengthening effects. The mean internal stress is defined as [54][55]:

$$
\sigma_{\text {matrix }}=\bar{E} \frac{\sum_{h k l} T_{h k l} m_{h k l} E_{h k l} \varepsilon_{h k l}}{\sum_{h k l} T_{h k l} m_{h k l} E_{h k l}},
$$

where $\bar{E}$ is the average Young's modulus of the ferritic matrix (with the values of $\bar{E}$ derived from previous study [45], and the fraction term is the mean internal strain defined as a weighted average lattice strain $\varepsilon_{h k l}$ for various $\{h k l\}$ reflections. The weighting parameters $T_{h k l}, m_{h k l}$ and $E_{h k l}$ are the texture index, the multiplicity and the stiffness for reflection $\{h k l\}$, respectively [56]. Here, six reflections were included in the calculation: $\{110\},\{200\},\{211\},\{310\},\{321\}$ and $\{222\}$. The 9YWTV and 14YWTsm13 were selected for detailed analysis, and a comparison of mean internal stress developed during the tensile and the externally applied stress are provided in Fig. 9. In all the tests at various temperatures, the mean internal stress was smaller than the actually applied stress after yielding, the difference is caused by the load re-distribution and transfer between phases and grains during plastic deformations. As the main strengthener in these alloys, nanoparticles play an important role in deformation particularly in the load re-distribution in plasticity. For 9YWTV, the difference between mean internal stress and externally applied stress is significant at room temperature, which decreased with an increase in temperature. At $600^{\circ} \mathrm{C}$, this difference is almost negligible (Fig. 9(a)). For 14YWT-sm13, the difference between mean internal stress and externally applied stress is significant at room temperature. The difference remains and cannot be neglected at $600^{\circ} \mathrm{C}$ (Fig. 9(b)). To better quantify the difference between mean internal stress

and external applied stress $\left(\sigma_{\text {applied }}\right)$, the strengthening factors $\mathrm{SF}=\left(\sigma_{\text {applied }}-\sigma_{\text {matrix }}\right) / \sigma_{\text {matrix }}$ [54] for both alloys, which are summarized in Table 4, were calculated. The larger SF of 14 YWT-sm 13 at $600^{\circ} \mathrm{C}$ shows that the strengthening of ferritic matrix mainly derives from the function of nanoparticles at room temperature and elevated temperatures. These ultra-fine uniformly distributed nanoparticles pin the dislocation movement, causing the loading transfer between the nanoparticles and the grains, therefore enhancing the strength of the material. In comparison, a significant decrease in SF from $500^{\circ} \mathrm{C}$ to $600^{\circ} \mathrm{C}$ was found in 9YWTV. This decrease indicates a higher temperature dependence of the strengthening for 9YWTV due to the lack of ultra-fine uniformly distributed nanoparticles, compared to 14YWT-sm13, particularly at the high-temperature regime. 


\section{CONCLUSIONS}

In this work, in-situ high-energy synchrotron X-ray diffraction tests were performed to study the basic mechanical properties and internal stress development of three types of NFAs: 9YWTV, 14YWTsm13, and 14YWT-sm170 at both room temperature and elevated temperatures. A combination of Kroner's model and X-ray measurements were used to derive the intrinsic monocrystal elastic-stiffness constants and polycrystal elastic parameters of the NFAs. An increase was observed in the elasticity anisotropy in all of the materials studied with an increase in temperature. An analysis of the intergranular strain of 14YWT-sm13 indicated a higher resistance to temperature softening compared to 9YWTV. A further analysis of the strengthening factors indicated differences in the applied and mean internal stress. This discrepancy was due to the nanoparticle strengthening mechanism. 14YWT-sm13 displays stronger strengthening compared to 9YWTV, particularly at the higher temperatures.

\section{ACKNOWLEDGEMENT}

We gratefully acknowledge the support of the Nuclear Energy University Program (NEUP) program under Award Number 13-5408 from the Department of Energy. This research used resources of the Advanced Photon Source, a U.S. Department of Energy (DOE) Office of Science User Facility Operated for the DOE Office of Science by Argonne National Laboratory under Contract No. DE-AC02$06 \mathrm{CH} 11357$.

\section{REFERENCES}

[1] S. Jitsukawa, A. Kimura, A. Kohyama, R.L. Klueh, A. A. Tavassoli, B. van der Schaaf, G. R. Odette, J. W. Rensman, M. Victoria, and C. Petersen, "Recent results of the reduced activation ferritic/martensitic steel development", Journal of Nuclear Materials 329, 39-46 (2004)

[2] M. S. El-Genk, and J.-M. Tournier, "A review of refractory metal alloys and mechanically alloyed-oxide dispersion strengthened steels for space nuclear power systems", Journal of Nuclear Materials 340, 93-112 (2005)

[3] R. L. Klueh, P. J. Maziasz, I. S. Kim, L. Heatherly, D. T. Hoelzer, N. Hashimoto, E. A. Kenik, and K. Miyahara, "Tensile and creep properties of an oxide-dispersion-strengthened ferritic steel", Journal of Nuclear Materials 307, 773-777 (2002)

[4] T. Hayashi, P. M. Sarosi, J. H. Schneibel, and M. J. Mills, "Creep response and deformation processes in nanocluster-strengthened ferritic steels", Acta Materialia 56, 1407-1416 (2008)

[5] G. R. Odette and D. T. Hoelzer, "Irradiation-tolerant nanostructured ferritic alloys: Transforming He from a liability to an asset", Journal of Material 62, 84-92 (2010)

[6] I. S. Kim, J. D. Hunn, N. Hashimoto, D. L. Larson, P. J. Maziasz, and K. Miyahara, "Defect and void evolution in oxide dispersion strengthened ferritic steels under 3.2 MeV Fe ion irradiation with simultaneous He injection", Journal of Nuclear Materials 280, 264-274 (2000)

[7] P. D. Edmondson, C. M. Parish, Y. Zhang, A. Hallen, and M. K. Miller, "He bubble distributions in a nanostructured ferritic alloy", Journal of Nuclear Materials 434, 210-216 (2013)

[8] K. Mo, D. Yun, Y. Miao, X. Liu, M. Pellin, J. Almer, J. Park, J. F. Stubbins, S. Zhu and A. M. Yacout, "Investigation of High-Energy Ion-Irradiated MA957 Using Synchrotron Radiation under In-Situ Tension", Materials 9(1), 15 (2016)

[9] G. R. Odette, M. J. Alinger, and B. D. Wirth, "Recent developments in irradiation-resistant steels", Annual Review of Materials Research 38, 471-503 (2008) 
[10] M. K. Miller, D. T. Hoelzer, E. A. Kenik, and K. F. Russell, "Stability of Ferritic MA/ODS alloys at high temperatures", Intermetallics 13, 387-392 (2005)

[11] J. Bentley and D. T. Hoelzer, "TEM Characterization of tensile-tested 14YWT nanostructured ferritic alloys", Microscopy and Microanalysis 14, 1416-1417 (2008)

[12] D. A. McClintock, D. T. Hoelzer, M. A. Sokolov, and R. K. Nanstad, "Mechanical properties of neutron irradiated nanostructured ferritic alloy 14YWT", Journal of Nuclear Materials 386-388, 307-311 (2009)

[13] M. K. Miller, E. A. Kenik, K. F. Russell, L. Heatherly, D. T. Hoelzer, and P. J. Maziasz, "Atom probe tomography of nanoscale particles in ODS ferritic alloys", Materials Science and Engineering: A 353, 140-145 (2003)

[14] R. Lindau, A. Moslang, M. Rieth, M. Klimiankou, E. Materna-Morris, A. Alamo, A. A. Tavassoli, C. Cayron, A. M. Lancha, P. Fernandez, and N. Baluc, "Present development status of EUROFER and ODS-EUROFER for application in blanket concepts", Fusion Engineering and Design 75, 989-996 (2005)

[15] C. A. Williams, E. A. Marquis, A. Cerezo, and G. D.Smith, "Nanoscale characterization of ODS-Eurofer 97 steel: An atom-probe tomography study", Journal of Nuclear Materials 400, 37-45 (2013)

[16] H. Zhao, C. L. Fu, M. Krcmar and M. K. Miller, "Effect of strain on the stabilization of oxygenenriched nanoclusters in Fe-based alloys", Physical Review B 84, 144115 (2011)

[17] C. L. Fu, M. Krcmar, G. S. Painter, and X. Q. Chen, "Vacancy mechanism of high oxygen solubility and nucleation of stable oxygen-enriched clusters in Fe", Physical Review Letters 99, 225502 (2007)

[18] L. L. Hsiung, M. J. Fluss, S. J. Tumey, B. W. Choi, Y. Serruys, F. Willaime, and A. Kimura, "Formation mechanism and the role of nanoparticles in Fe-Cr ODS steels developed for radiation tolerance", Physical Review B 82, 184103 (2010)

[19] M. K. Miller, C. L. Fu, M. Krcmar, D. T. Hoelzer, and C. T. Liu, "Vacancies as a constitutive element for the design of nanocluster-strengthened ferritic steels", Frontiers of Materials Science in China 3(1), 9-14 (2009)

[20] M. K. Miller, K. F. Russell, D. T. Hoelzer, "Characterization of precipitates in MA/ODS ferritic alloys", Journal of Nuclear Materials 351, 261-268 (2006)

[21] M. K. Miller, and C. M. Parish, "Role of alloying elements in nanostructured ferritic steels", Materials Science and Technology 27(4), 729-734, (2013)

[22] D. J. Larson, P. J. Maziasz, I. S. Kim, and K. Miyahara, "Three-dimensional atom probe observation of nanoscale titanium-oxygen clustering in an oxide-dispersion-strengthened $\mathrm{Fe}$ 12Cr-3W-0.4Ti $+\mathrm{Y}_{2} \mathrm{O}_{3}$ ferritic alloy", Scripta Materialia 44, 359-364 (2001)

[23] P. Pareige, M. K. Miller, R. E. Stoller, D. T. Hoelzer, E. Cadel, and B. Radiguet, "Stability of nanometer-sized oxide clusters in mechanically-alloyed steel under ion-induced displacement cascade damage conditions", Journal of Nuclear Materials 360, 136-142 (2007)

[24] J. He, F. Wan, K. Sridharan, T. R. Allen, A. Certain, V. Shutthanandan, and Y.Q. Wu, "Stability of nanoclusters in 14YWT oxide dispersion strengthened steel under heavy ion-irradiation by atom probe tomography", Journal of Nuclear Materials 455, 41-45 (2014)

[25] J. H. Kim, T. S. Byun, D. T. Hoelzer, S. W. Kim, and B. H. Lee, "Temperature dependence of strengthening mechanisms in the nanostructured ferritic alloy 14YWT: Part I Mechanical and microstructural observations", Materials Science \& Engineering A 559, 101-110 (2013) 
[26] Y. Miao, K. Mo, Z. Zhou, X. Liu, K. C. Lan, G. Zhang, M. K. Miller, K. A. Powers and J. F. Stubbins, "Size-dependent characteristics of ultra-fine oxygen-enriched nanoparticles in austenitic steels", Journal of Nuclear Materials 480, 195-201 (2016)

[27] G. Zhang, Z. Zhou, K. Mo, Y. Miao, S. Li, X. Liu, M. Wang, J. S. Park, J. Almer, and J. F. Stubbins, "The comparison of microstructures and mechanical properties between $14 \mathrm{Cr}-\mathrm{Al}$ and 14Cr-Ti ferritic ODS alloys", Materials \& Design 98, 61-67 (2016)

[28] G. Zhang, Z. Zhou, K. Mo, P. Wang, Y. Miao, S. Li, M. Wang, X. Liu, M. Gong, J. Almer and J. F. Stubbins, "The microstructure and mechanical properties of Al-containing 9Cr ODS ferritic alloy", Journal of Alloys and Compounds 648, 223-228 (2015)

[29] E. Kroner, "On the plastic deformation of polycrystals", Acta Metallurgica 9, 155-161(1961)

[30] J. L. Lin, K. Mo, D. Yun, Y. Miao, X. Liu, H. Zhao, D. T. Hoelzer, J. S. Park, J. Almer, G. Zhang, and Z. Zhou, "In situ synchrotron tensile investigations on 14YWT, MA957, and 9-Cr ODS alloys", Journal of Nuclear Materials 471, 289-298 (2016)

[31] G. Zhang, K. Mo, Y. Miao, X. Liu, J. Almer, Z. Zhou, and J. F. Stubbins, "Load partitioning between ferrite/martensite and dispersed nanoparticles of a $9 \mathrm{Cr}$ ferritic/martensitic (F/M) ODS steel at high temperatures", Materials Science \& Engineering A 637, 75-81 (2015)

[32] T. S. Byun, J. H. Yoon, S. H. Wee, D. T. Hoelzer, and S. A. Maloy, "Fracture behavior of 9Cr nanostructured ferritic alloy with improved fracture toughness", Journal of Nuclear Materials 449, 39-48 (2014).

[33] T. S. Byun, J. H. Yoon, D. T. Hoelzer, Y. B. Lee, S. H. Kang, and S. A. Maloy, "Process development for 9Cr nanostructured ferritic alloy (NFA) with high fracture toughness", Journal of Nuclear Materials 449, 290-299 (2014)

[34] D. T. Hoelzer, K. A. Unocic, W. Tang, and Z. Feng, "Status of Joining Thin Sheet and Thin Wall Tubes of 14YWT", (No. ORNL/TM-2015/548), Oak Ridge National Laboratory (ORNL), Oak Ridge, TN (United States), (2015)

[35] D. T. Hoelzer, K. A. Unocic, M. A. Sokolov, and T. S. Byun, "Influence of processing on the microstructure and mechanical properties of 14YWT", Journal of Nuclear Materials 471, 251265 (2016)

[36] J. Bentley, D. T. Hoelzer, D. W. Coffey, and K. A. Yarborough, "EFTEM and spectrum imaging of mechanically alloyed oxide-dispersion-strengthened 12YWT and 14YWT ferritic steels", Microscopy and microanalysis 10, 662-663 (2004)

[37] D. Qu, K. D. Liss, Y. Sun, M. Reid, J. Almer, K. Yan, Y. Wang, X. Liao, and J. Shen, "Structural origins for the high plasticity of a $\mathrm{Zr}-\mathrm{Cu}-\mathrm{Ni}-\mathrm{Al}$ bulk metallic glass", Acta Materialia 61, 321-330 (2013)

[38] K. Mo, Z. Zhou, Y. Miao, D. Yun, H. M. Tung, G. Zhang, W. Chen, J. Almer, and J. F. Stubbins, "Synchrotron study on load partitioning between ferrite/martensite and nanoparticles of a $9 \mathrm{Cr}$ ODS steel", Journal of Nuclear Materials 455, 376-381 (2014)

[39] Y. Miao, K. Mo, B. Cui, W. Y. Chen, M. K. Miller, K. A. Powers, V. McCreary, D. Gross, J. Almer, and I. M. Robertson, "The interfacial orientation relationship of oxide nanoparticles in a hafnium-containing oxide dispersion-strengthened austenitic stainless steel", Materials Characterization 101, 136-143 (2015)

[40] X. Pan, X. Wu, X. Chen, K. Mo, J. Almer, D. R. Haeffner, and J. F. Stubbins, “Temperature and particle-size effects on flow localization of $9-12 \% \mathrm{Cr}$ ferritic/martensitic steel by in situ X-ray diffraction and small angle scattering", Journal of Nuclear Materials 398, 220-226 (2010) 
[41] X. Pan, X. Wu, K. Mo, X. Chen, J. Almer, J. Ilavsky, D. R. Haeffner, and J. F. Stubbins, "Lattice strain and damage evolution of $9-12 \% \mathrm{Cr}$ ferritic/martensitic steel during in situ tensile test by X-ray diffraction and small angle scattering", Journal of Nuclear Materials 407, 10-15 (2010)

[42] B. B. He, "Introduction to two-dimensional X-ray diffraction," Powder diffraction 18, 71-85 (2003)

[43] M. L. Young, J. D. Almer, M. R. Daymond, D. R. Haeffner, and D. C. Dunand, "Load partitioning between ferrite and cementite during elastoplastic deformation of an ultrahighcarbon steel", Acta materialia 55, 1999-2011 (2007)

[44] P. Hedström, L. E. Lindgren, J. Almer, U. Lienert, J. Bernier, M. Terner, and M. Odén, "Load partitioning and strain-induced martensite formation during tensile loading of a metastable austenitic stainless steel", Metallurgical and Materials Transactions A 40, 1039-1048 (2009)

[45] S. Cheng, Y. D. Wang, H. Choo, X. L. Wang, J. D. Almer, P. K. Liaw, and Y. K. Lee, “An assessment of the contributing factors to the superior properties of a nanostructured steel using in situ high-energy X-ray diffraction”, Acta Materialia 58, 2419-2429 (2010)

[46] M. T. Hutchings, P. J. Withers, T. M. Holden, and T. Lorentzen, "Introduction to the characterization of residual stress by neutron diffraction", CRC press, (2005)

[47] I. C. Noyan and J. B. Cohen, "Residual stress: measurement by diffraction and interpretation", Springer, (2013)

[48] J. D. Eshelby, "The Determination of the Elastic Field of an Ellipsoidal Inclusion, and Related Problems", Proceedings of the Royal Society of London A: Mathematical, Physical and Engineering Sciences 241, 376-396 (1957)

[49] C. N. Tomé, "Tensor properties of textured polycrystals", Chapter 7, pp. 282-324 in Texture and anisotropy, edited by U. F. Kocks et al., Cambridge University Press, (1998)

[50] G. M. Stoica, A. D. Stoica, M. K. Miller, and D. Ma, "Temperature dependent elastic anisotropy and mesoscale deformation in a nanostructured ferritic alloy", Nature communication, 5 (2014)

[51] W. L. Pang, T. M. Holden, and T. E. Mason, "In situ generation of intergranular strains in an A17050 alloy”, Acta Materialia 46, 1503-1518 (1998)

[52] T. M. Holden, R. A. Holt, and J. W. L. Pang, "Intergranular stresses in ZIRCALOY-2", Materials Transactions A 33, 749-755 (2002)

[53] M. R. Daymond, C. N. Tome, and M. A. M. Bourke, "Measured and predicted intergranular strains in textured austenitic steel", Acta Materialia 48, 553-564 (2000)

[54] G. Zhang, Z. Zhou, K. Mo, Y. Miao, X. Liu, J. Almer, and J. F. Stubbins, "The evolution of internal stress and dislocation during tensile deformation in a $9 \mathrm{Cr}$ ferritic/martensitic (F/M) ODS steel investigated by high-energy X-rays”, Journal of Nuclear Materials 467, 50-57 (2015)

[55] M. R. Daymond, "The determination of a continuum mechanics equivalent elastic strain from the analysis of multiple diffraction peaks", Journal of Applied Physics 96, 4263 (2004)

[56] B. D. Cullity, "Elements of X-ray Diffraction", Prentice Hall $3^{\text {rd }}$ edition, (2001) 


\begin{tabular}{|c|c|c|c|c|}
\hline & T $\left({ }^{\mathbf{0}} \mathbf{C}\right)$ & 9YWTV & $\begin{array}{l}\text { 14YWT } \\
\text {-sm13 }\end{array}$ & $\begin{array}{l}\text { 14YWT } \\
\text {-sm170 }\end{array}$ \\
\hline \multirow{4}{*}{$\approx$} & RT & 1.78 & 1.38 & 1.10 \\
\cline { 2 - 5 } & 300 & 1.55 & 1.12 & 1.00 \\
\cline { 2 - 5 } & 500 & 1.34 & 0.90 & 0.59 \\
\cline { 2 - 5 } & 600 & 0.67 & 0.78 & 0.52 \\
\hline \multirow{4}{*}{$\approx$} & $\mathrm{RT}$ & 1.48 & 1.11 & 0.87 \\
\cline { 2 - 5 } & 300 & 1.19 & 0.84 & 0.73 \\
\cline { 2 - 5 } & 500 & 0.54 & 0.46 & 0.50 \\
\cline { 2 - 5 } & 600 & 0.47 & 0.44 & 0.37 \\
\hline
\end{tabular}

Table 1: Ultimate tensile strengths (UTS) and yield strengths (YS) of the NFAs at various temperatures: (units: GPa).

\begin{tabular}{|c|c|c|c|c|c|c|c|}
\hline \multirow[t]{2}{*}{$\mathbf{T}$} & \multirow[t]{2}{*}{ Sample } & \multicolumn{6}{|c|}{ Fitted Elastic modulus $E_{h k l}$ for each peak (GPa) } \\
\hline & & $\left\{\begin{array}{lll}1 & 1 & 0\end{array}\right\}$ & $\left\{\begin{array}{lll}2 & 0 & 0\end{array}\right\}$ & $\left\{\begin{array}{lll}2 & 1 & 1\end{array}\right\}$ & $\{220\}$ & $\left\{\begin{array}{lll}3 & 1 & 0\end{array}\right\}$ & $\{222\}$ \\
\hline \multirow{3}{*}{$\underline{\underline{z}}$} & 9YWTV & 215 & 181 & 219 & 218 & 196 & 233 \\
\hline & 14YWT-sm13 & 236 & 175 & 214 & 233 & 193 & 231 \\
\hline & 14YWT-sm170 & 231 & 178 & 205 & 236 & 198 & $\mathrm{NaN}$ \\
\hline \multirow{3}{*}{$\begin{array}{l}\text { U } \\
\text { o̊ }\end{array}$} & 9YWTV & 160 & 129 & 189 & 177 & 153 & 261 \\
\hline & 14YWT-sm13 & 198 & 140 & 201 & 198 & 159 & 244 \\
\hline & 14YWT-sm170 & 172 & 153 & 179 & 179 & 156 & $\mathrm{NaN}$ \\
\hline
\end{tabular}

Table. 2. Elastic modulus for various $\{h k l\}$ reflection; the uncertainty of the values is around $\pm 5 \mathrm{GPa}$. 


\begin{tabular}{|c|c|c|c|c|c|c|}
\hline & \multicolumn{3}{|c|}{ 9YWTV } & \multicolumn{3}{|c|}{ 14YWT-sm13 } \\
\hline $\mathbf{T}\left({ }^{\mathbf{0}} \mathbf{C}\right)$ & $\mathbf{C}_{\mathbf{1 1}}$ & $\mathbf{C}_{\mathbf{1 2}}$ & $\mathbf{C}_{\mathbf{4 4}}$ & $\mathbf{C}_{\mathbf{1 1}}$ & $\mathbf{C}_{\mathbf{1 2}}$ & $\mathbf{C}_{\mathbf{4 4}}$ \\
\hline $\mathbf{R T}$ & 213.0 & 109.0 & 119.0 & 199.0 & 77.0 & 111.0 \\
\hline $\mathbf{3 0 0}$ & 202.0 & 97.0 & 125.0 & 172.0 & 65.5 & 99.5 \\
\hline $\mathbf{5 0 0}$ & 194.0 & 119.0 & 125.0 & 186.0 & 122.0 & 111.0 \\
\hline $\mathbf{6 0 0}$ & 186.0 & 135.0 & 131.0 & 187.0 & 125.0 & 129.0 \\
\hline
\end{tabular}

Table 3. The best fit of elastic-stiffness constants using Eq. (5). The unit is GPa.

\begin{tabular}{|l|l|l|l|l|}
\hline Sample & RT & $\mathbf{3 0 0}^{\circ} \mathbf{C}$ & $\mathbf{5 0 0}^{\mathbf{}} \mathbf{C}$ & $\mathbf{6 0 0}^{\circ} \mathbf{C}$ \\
\hline 9YWTV & 0.1612 & 0.1660 & 0.1937 & 0.0818 \\
\hline 14YWT-sm13 & 0.2114 & 0.4636 & 0.1819 & 0.2304 \\
\hline
\end{tabular}

Table. 4. The strengthening factors (SFs) for 9YWTV and 14YWT-sm13 at various temperatures. 


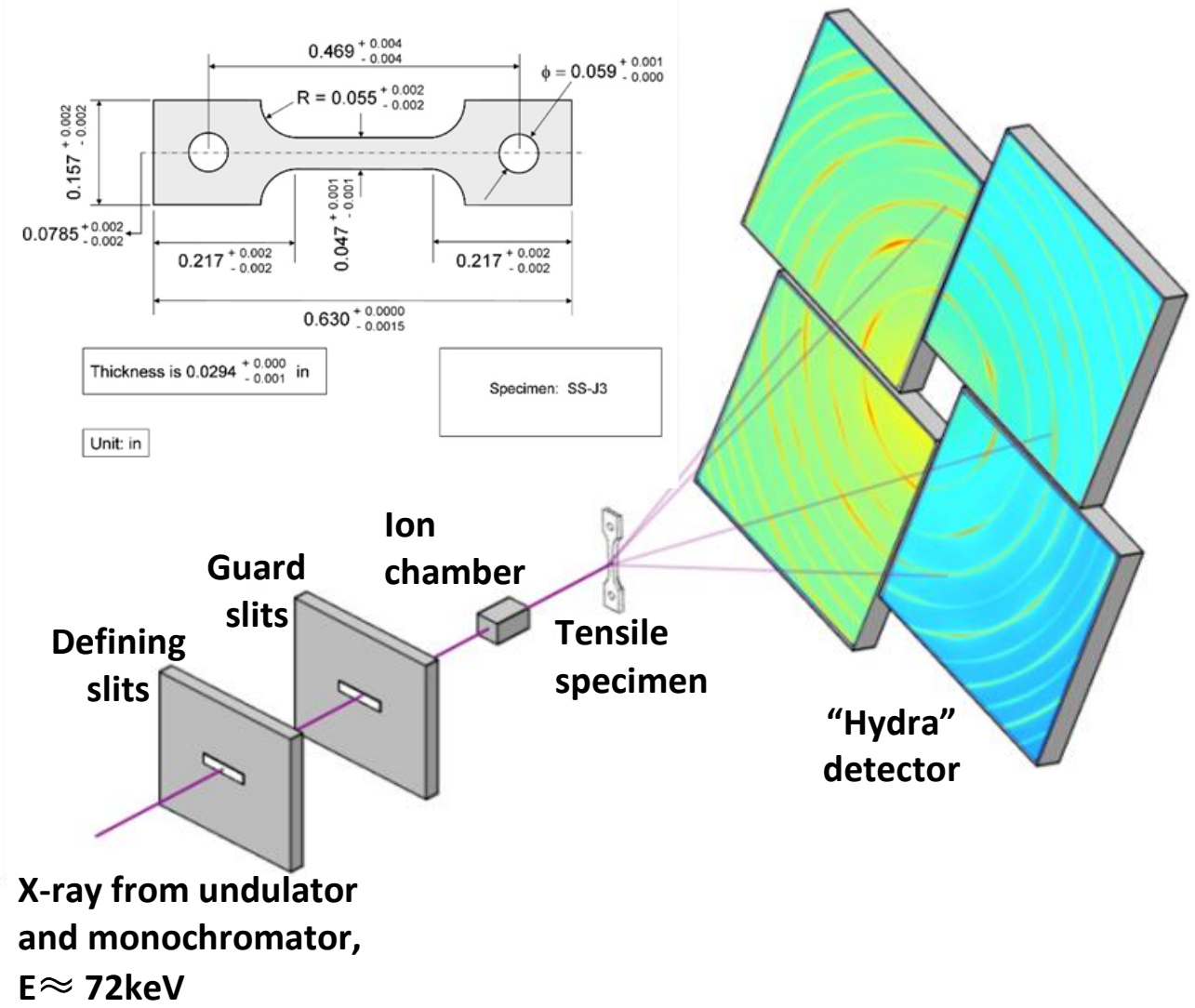

Figure 1. In-situ synchrotron X-ray diffraction test setup.
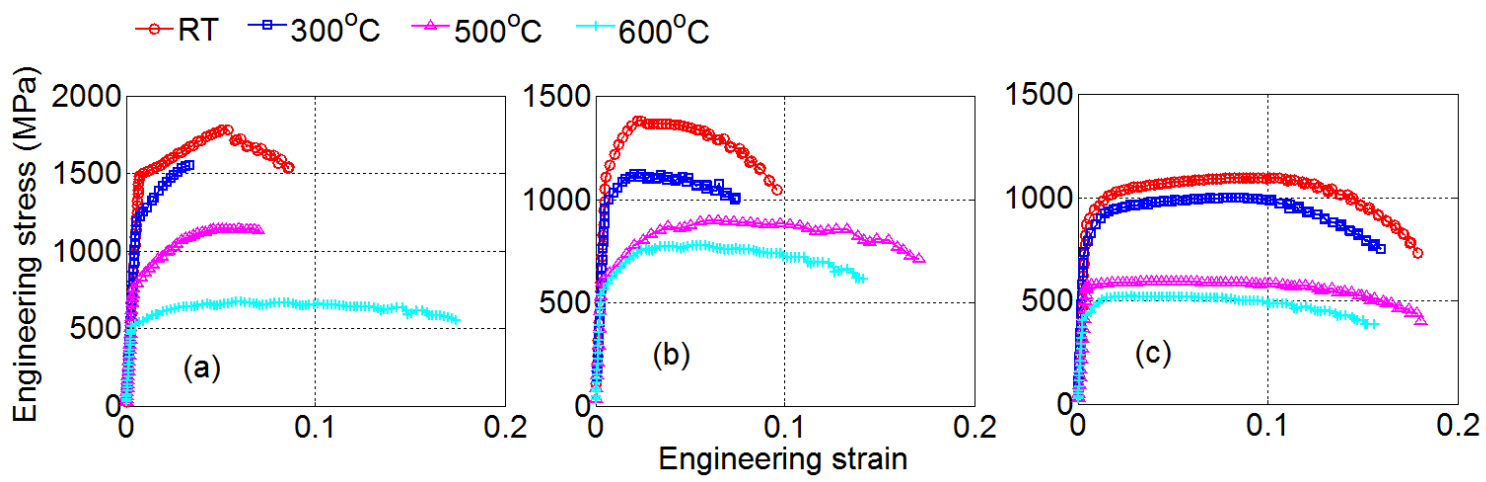

Figure 2. Stress-strain diagrams of the tested NFAs: (a) 9YWTV; (b) 14YWT-sm13; and (c) 14YWTsm170 at various temperatures. 


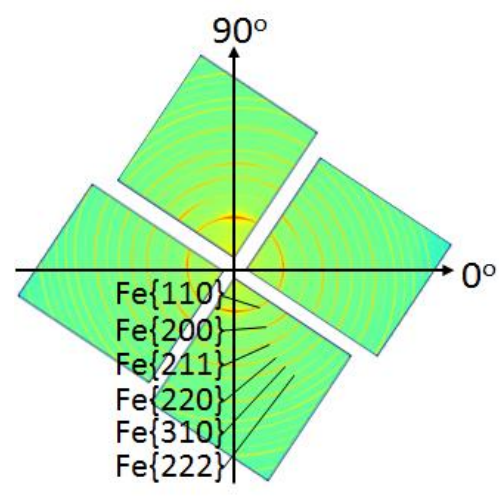

(a)

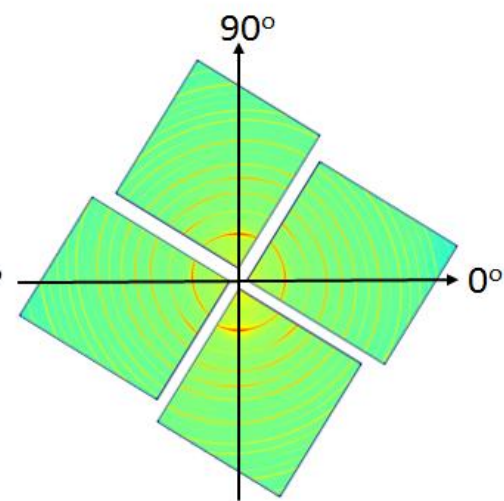

(b)

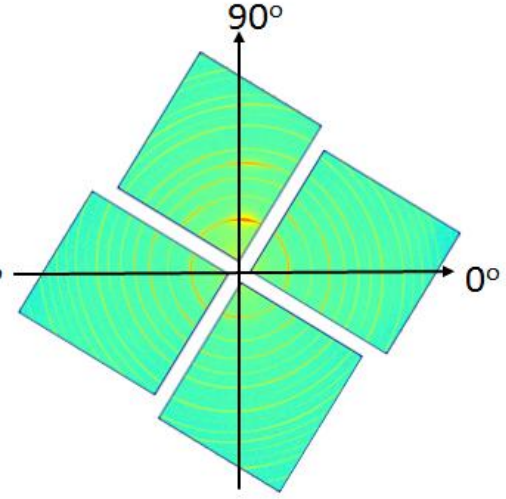

(c)

Figure 3. Diffraction patterns for (a) 9YWTV, (b) 14YWT-sm13, and (c) 14YWT-sm170. " 90 " " denotes the tensile loading direction.

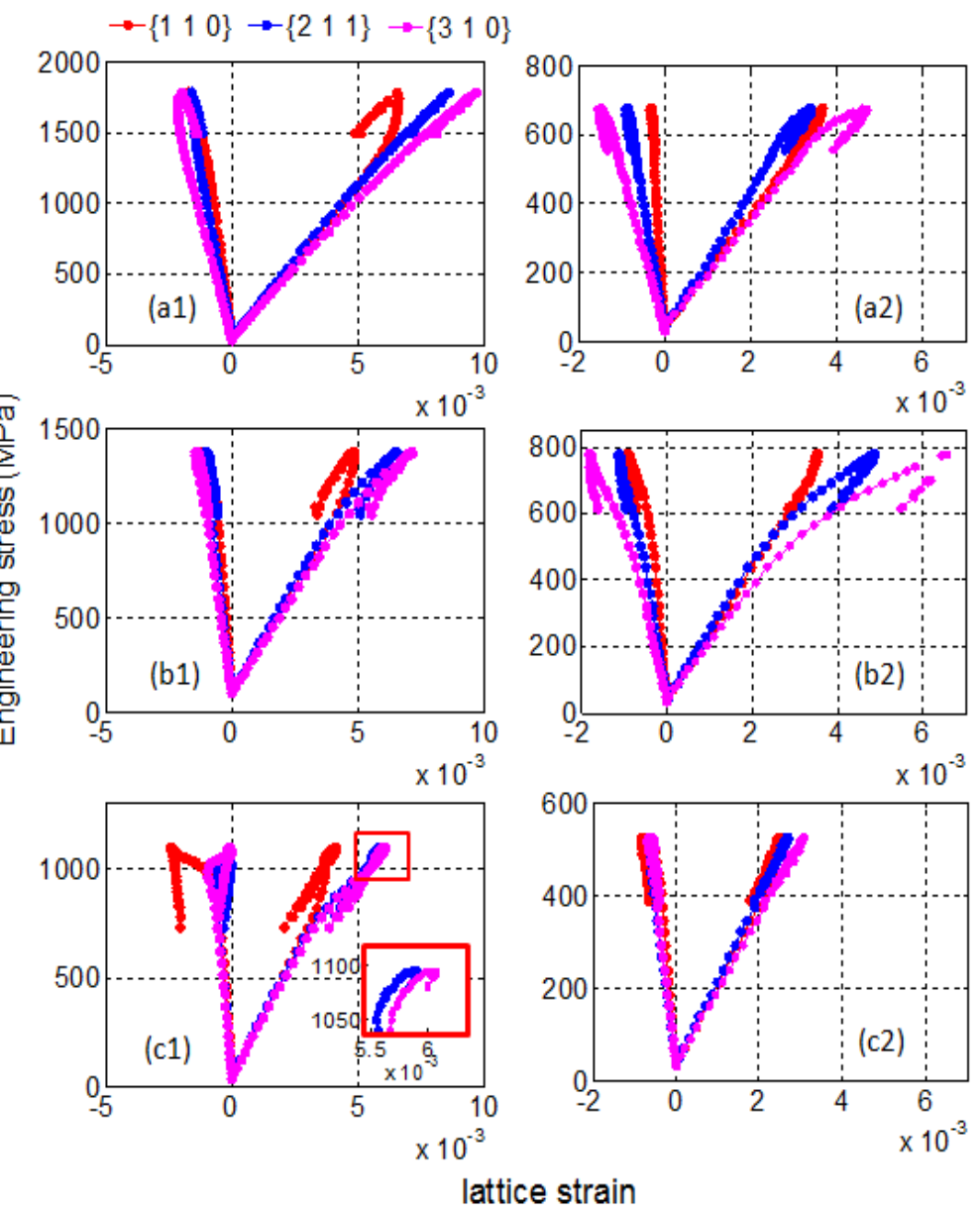

Figure 4. Lattice strain - applied stress relations of three NFAs at room temperature: (a1) 9YWTV; (b1) 14YWT-sm13; (c1) 14YWT-sm170; and at $600^{\circ} \mathrm{C}$ : (a2) 9YWTV; (b2) 14YWTsm13; (c2) 14YWT-sm170. 


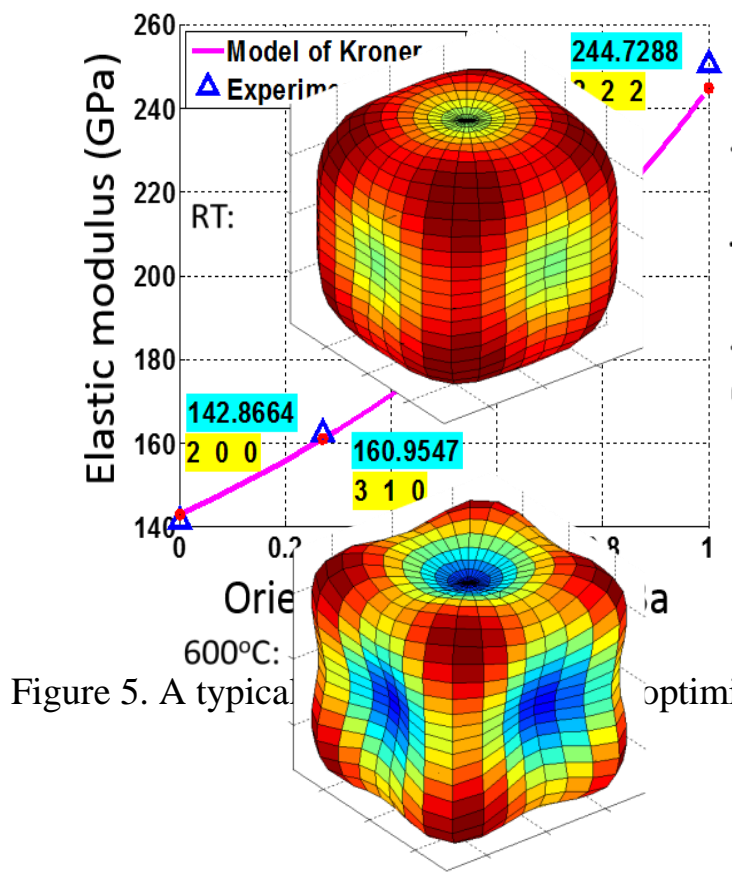

(a)

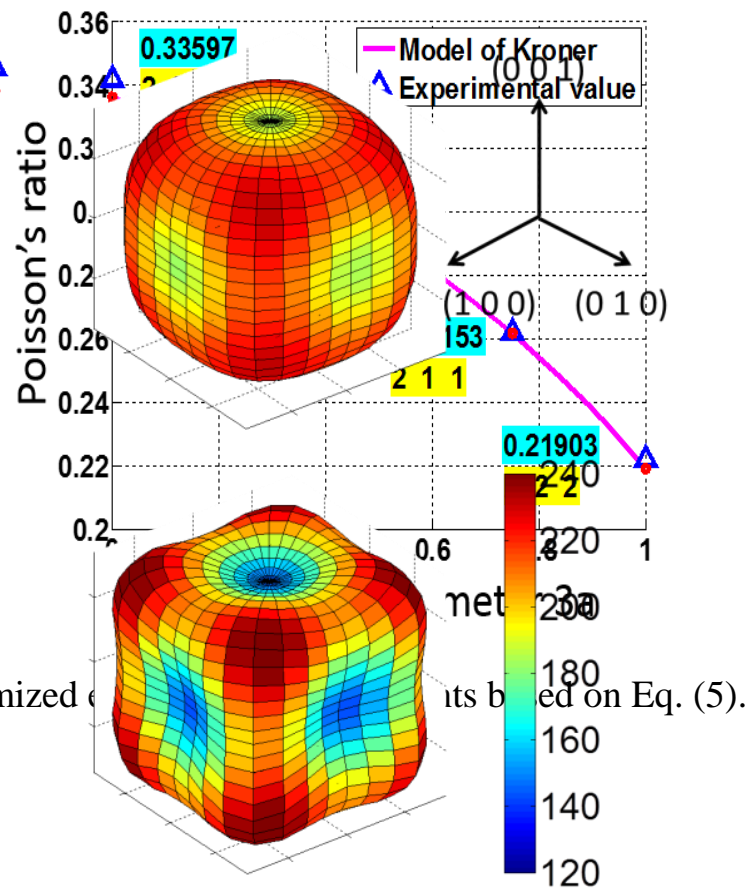

(b)

Figure 7. Orientation dependence of Young's modulus (unit: GPa) at RT and $600^{\circ} \mathrm{C}$ for (a) 9YWTV and (b) 14YWT-sm13.
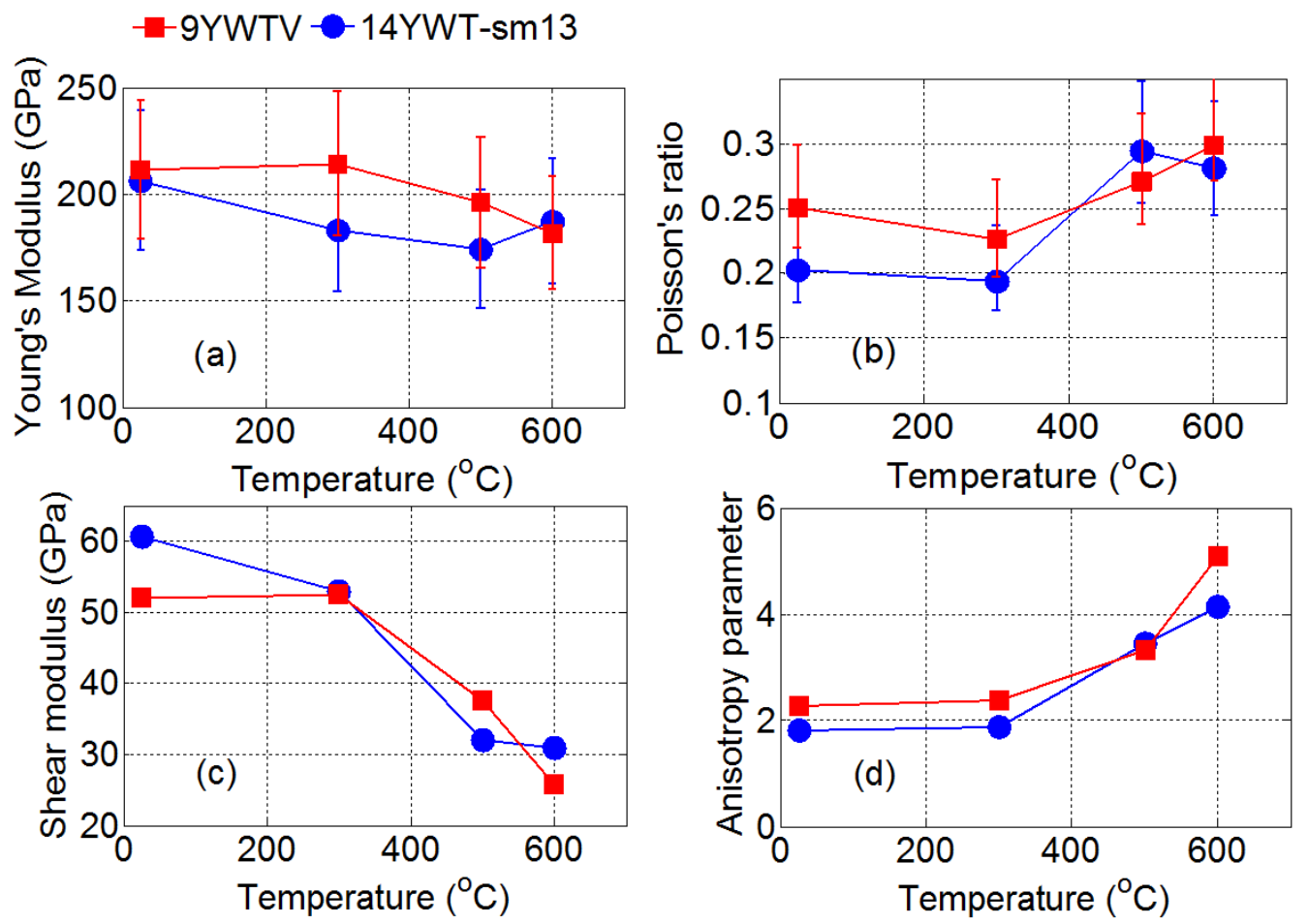

Figure 6. Temperature dependence of elastic mechhfical properties for the NFAs: (a) The bulk elastic modulus; (b) Poisson's ratio (c) shear modulus; and (d) anisotropy parameter evolution. 

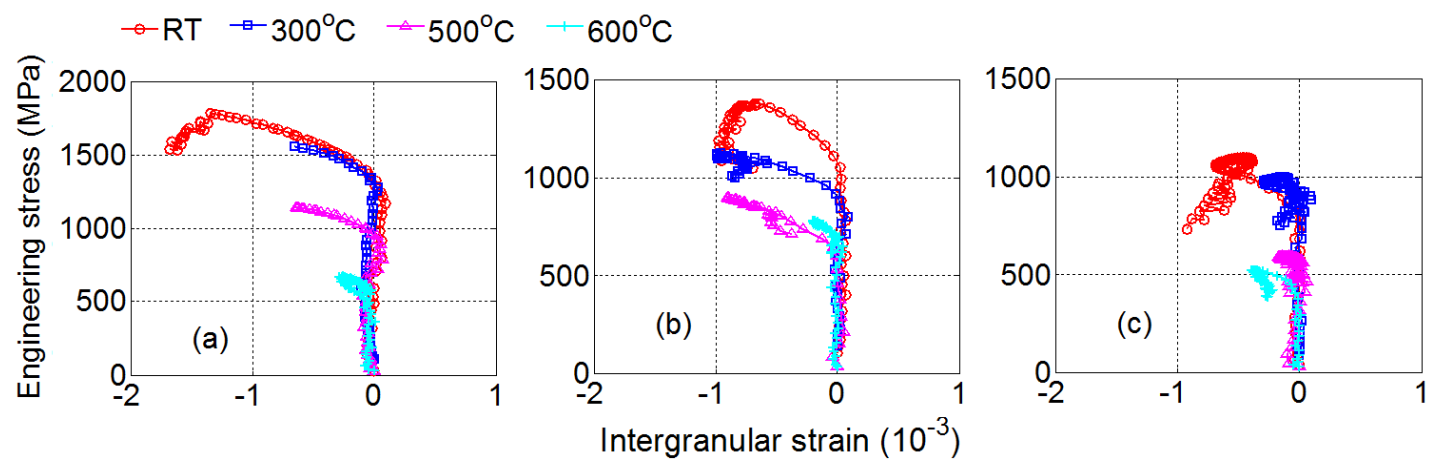

Figure 8. Intergranular strain evolution for the NFAs (a) 9YWTV, (b) 14YWT-sm13, and (c) 14YWTsm170. 

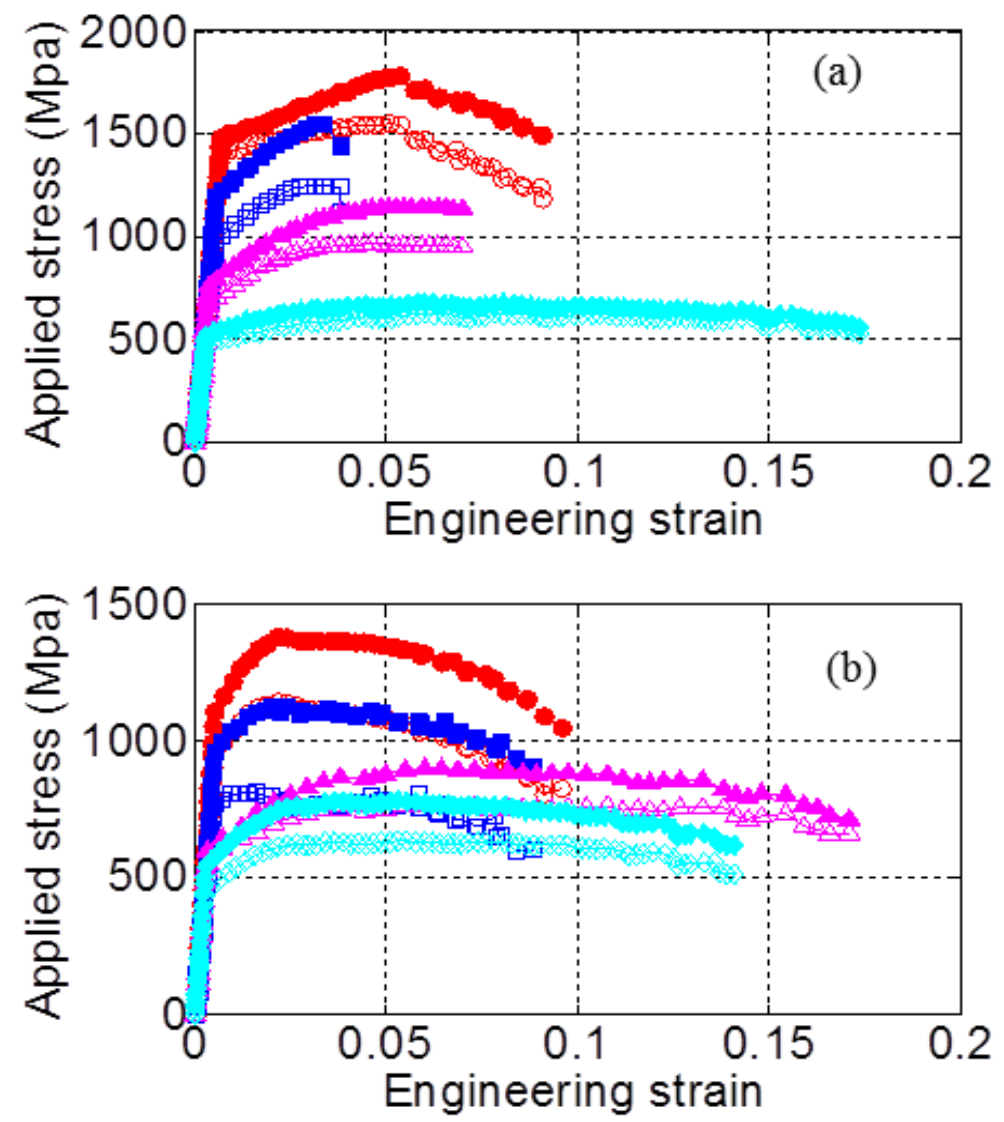

Fig. 9: Comparison of mean internal stress and applied stress for (a) 9YWTV and (b) 14YWTsm13 at various temperatures (Red: RT; Blue: $300^{\circ} \mathrm{C}$; Magenta: $500^{\circ} \mathrm{C}$; and Cyan: $600^{\circ} \mathrm{C}$ ). The solid symbols and hollow symbols are applied stresses and internal stresses, respectively. 